\title{
A LIVRE INICIATIVA NA PÓS-MODERNIDADE: O FENÔMENO DO CROWDFUNDING SOB A PERSPECTIVA DA SOLIDARIEDADE SOCIAL
}

\author{
Mariana Ribeiro Santiago* \\ Bruno Modesto Silingardi**
}

\begin{abstract}
RESUMO
O presente artigo, fundado nas transformações da economia desde o Estado Liberal até os dias atuais, tem como finalidade demonstrar as mudanças da livre iniciativa no panorama da pósmodernidade, avançando para o desenvolvimento social e sustentável. Nesse contexto, baseado no método dedutivo, na pesquisa documental e bibliográfica, o artigo aborda o surgimento de novas modalidades empresariais que atendam à expectativa da solidariedade e sustentabilidade, dentre as quais será analisado especificamente o Crowdfunding. Em conclusão, nota-se que os benefícios trazidos pelo financiamento coletivo atendem os parâmetros da solidariedade social e sustentabilidade, mostrando-se uma importante ferramenta para o alcance do bem comum.
\end{abstract}

PALAVRAS-CHAVE: Crowdfunding; Livre Iniciativa; Solidariedade social.

\section{THE FREE INITIATIVE IN POST-MODERNITY: THE PHENOMENON OF CROWNFUNDING UNDER THE PERSPECTIVE OF THE SOCIAL SOLIDARITY}

\begin{abstract}
The present article, based on changes in the economy since the Liberal State up to the actuality, has to demonstrate of freedom of enterprise the post-modernity, in progress to social development and sustainable. In this context, based on the deductive approach, documentary and bibliographic research, the article will discuss the emergence of new forms that business meet the expectations of solidarity and sustainability, among which will be examined the Crowdfunding. In conclusion, it is noted that the benefits brought by collective financing meet the parameters of social solidarity and sustainability, proving to be an instrument for achieving the common good.
\end{abstract}

KEYWORDS: Crowdfunding; Free Initiative; Social solidarity.

\footnotetext{
* Doutora e Mestre em Direito Civil Comparado pela Pontifícia Universidade Católica de São Paulo (PUC-SP). Professora do Programa de Mestrado e Doutorado em Direito da Universidade de Marília (UNIMAR). Contato: mariana@nbsadvogados.com.br

* * Mestrando em Direito pela Universidade de Marília (UNIMAR). Especialista em Direito Empresarial pela UEL. Advogado Corporativo. Contato: bruno.silingardi@yahoo.com.br.
} 


\section{INTRODUÇÃO}

O declínio do Estado Liberal limitou a atuação das atividades empresariais, cujos abusos adstritos à liberdade econômica passaram a ser coibidos pela ação do poder estatal. A liberdade e propriedade, fatores implícitos ao sistema capitalista, perderam a autonomia conferida pelo liberalismo, surgindo a necessidade de equalizar a produção de riquezas e a exploração do trabalho humano, valores estes introduzidos no texto constitucional por influência do Estado Social.

A partir da Constituição Federal de 1988, houve a positivação da dignidade da pessoa humana na condição de princípio constitucional conformador, ensejando alterações marcantes no funcionamento da ordem econômica pátria, baseada até então nas conquistas do sistema liberal. Dessa maneira, o exercício das atividades econômicas após o advento da lei maior assumiu o papel de auxiliar o desenvolvimento econômico e social do país, mediante a observância cumulativa dos valores sociais do trabalho e da livre iniciativa, por força do artigo 170 da Carta Política.

Nessa senda, as empresas pós-modernas modificaram o modo de produção tradicional, ou seja, deixaram de focar exclusivamente no lucro, a fim de desenvolver atividades rentáveis e, simultaneamente, equilibradas, com foco na função social e solidária, sendo esta última inserida no rol de objetivos do Estado Democrático e materializada no artigo $3^{\circ}$, inciso I, da Constituição Federal.

Observa-se, portanto, na sociedade pós-moderna, inúmeros exemplos de negócios desenvolvidos sob a perspectiva da função solidária, sendo um deles o financiamento coletivo. Trata-se de modelo inovador de geração de capital, cujo custeio é promovido pela integração de pessoas que promovem o desembolso de valores captados pela plataforma digital e posteriormente revertidos à realização de projetos geralmente de ordem social ou mesmo para constituição de empresas sustentáveis e adeptas do formato de economia participativa.

Nessas condições, o objetivo desse trabalho é demonstrar a evolução da livre iniciativa, diante dos impactos da função solidária e dos aspectos inerentes à sustentabilidade. Além disso, mostra-se como proposta deste artigo examinar a operacionalidade do Crowdfunding à luz do sistema jurídico.

A escolha do tema se justifica pela necessidade de identificação, estudo e aplicação de formas alternativas de captação de recursos para projetos em benefício de pequenas empresas 
e da sociedade civil, diante de quadros de crise econômica, como perspectiva de desenvolvimento pela via solidária.

Para alcançar o resultado almejado no presente estudo, será utilizado, o método dedutivo na abordagem, partindo de regras gerais para a compreensão de casos específicos, com recurso à pesquisa bibliográfica e documental.

\section{A LIVRE INICIATIVA NA SOCIEDADE PÓS-MODERNA}

A liberdade individual, característica precípua do Estado Liberal, encarregou-se de fomentar o início das atividades empresariais, emancipando a regulação da economia sem a intervenção do poder estatal. Na sequência, a revolução industrial alterou a sistemática de manufatura, conferindo celeridade na fabricação de bens que passaram a ser produzidos em larga escala. O livre comércio entre os países emergiu e se destacou dentre as principais soluções para o desenvolvimento econômico, trazendo riqueza às nações e permitindo a cumulação de capital, principal fator de concentração de poder e aumento da desigualdade econômica e financeira entre os entes da sociedade.

Para Giddens ${ }^{1}$ "no final do século XIX já havia uma economia global aberta, com considerável quantidade de comércio, inclusive comércio de moedas". O incessante desejo pelo lucro proveniente dos atos comerciais impulsionou o regime capitalista que, ao longo do tempo, incentivou a expansão dos negócios e resultou na cumulação de riquezas.

Anota-se, entretanto, sob o prisma da justiça social, que algumas mudanças trazidas pelo movimento liberal e capitalista não foram positivas, trazendo miséria e revolta da população, representada em maior proporção pelo proletariado. A liberdade que, tempos antes, fora alvo principal das revoluções sociais assume conotação visivelmente negativa. A permissibilidade do Estado cria condições favoráveis à formação do poder econômico e na concentração de riquezas que, por sua vez, resultava no aumento da desigualdade social.

A economia de mercado, diferentemente da auto regulação e do equilíbrio que seria obtido a partir do "Laissez faire", produziu efeito completamente contrário à teoria defendida por Adam Smith, uma vez que "quanto menos palpável a presença do Estado nos atos da vida

\footnotetext{
${ }^{1}$ GIDDENS, Anthony. Mundo em descontrole. 6 ed. Rio de Janeiro: Record, 2007. p. 20.
} 
humana, mais larga e generosa a esfera de liberdade outorgada ao indivíduo. Caberia a este fazer ou deixar de fazer o que lhe aprouvesse" ${ }^{2}$.

Desse modo, a mínima intervenção do Estado, sem dúvidas, permitiu o crescimento do comércio e, com isso, a burguesia se enriqueceu, em detrimento da mão de obra da classe operária, formando um abismo entre os fortes empresários e os desvalorizados trabalhadores que, além de segregados e explorados não dispunham do mínimo necessário à existência digna.

No tocante ao resultado negativo do liberalismo, Fabio Konder Comparato ${ }^{3}$ faz severas críticas ao movimento capitalista:

Enquanto o capital é, por assim dizer, personificado e elevado à dignidade do sujeito de direito, o trabalhador é aviltado à condição de mercadoria, de mero insumo no processo de produção, para ser ultimamente, na fase de fastígio do capitalismo financeiro, dispensado e relegado ao lixo social como objeto descartável.

Analisando os graves danos sociais decorrentes do liberalismo, Paulo Bonavides ${ }^{4}$ assevera que o livre arbítrio conferido aos empresários em virtude do afastamento do poder estatal, "evidencia, com a liberdade do contrato, a desumana espoliação do trabalho, o doloroso emprego de métodos brutais de exploração econômica, a que nem a servidão medieval se poderia, com justiça, equiparar".

O Estado Social assume, nesse momento, papel importante na tentativa de equilibrar a criação de riqueza e proporcionar o bem estar da coletividade. Enquanto o sistema capitalista, amparado na liberdade formal, sofre restrições por intermédio de políticas estatais, a classe operária inicia o processo de conquistas dos direitos e garantias individuais que aos poucos começam ser disciplinados em normas constitucionais, que visam proteger e valorizar o trabalho humano como um dos pilares para alcançar o desenvolvimento social.

O primeiro fator econômico adaptado ao modelo social foi a propriedade, com a promulgação da Constituição Federal de 1934, os detentores de bens de natureza mobiliária e imobiliária foram compelidos a observar a função social, de modo que a concentração de riqueza seja utilizada como ferramenta para conter as "injustiças sociais e econômicas do mundo capitalista"

\footnotetext{
${ }^{2}$ BONAVIDES, Paulo. Do Estado liberal ao Estado social. 9 ed. São Paulo: Malheiros Editores, 2009. p. 60.

${ }^{3}$ COMPARATO, Fábio Konder. A afirmação histórica dos direitos humanos. 7.ed. rev. e atual. São Paulo: Saraiva, 2010. p.36.

${ }^{4}$ BONAVIDES, Paulo. Do Estado liberal ao Estado social. 9 ed. São Paulo: Malheiros Editores, 2009, p. 59.

${ }^{5}$ Ibid., p. 60.
} 
Pautada na concepção de "liberdade positiva", construída com fundamento nos elementos marcantes do Estado Social Moderno, a Constituição Federal de 1988 normatizou a função social e, com isso, além de delimitar o uso da propriedade, segundo os ditames da justiça social, conforme previsto no artigo $5^{\circ}$, inciso XXIII, preocupou-se em regulamentar, no artigo 170, os princípios que regem a ordem econômica, sobre a qual se destaca o primado da livre iniciativa, cuja eficácia está inteiramente condicionada a valorização do trabalho humano.

No tocante a amplitude dos princípios norteadores da ordem econômica, Eros Grau ${ }^{6}$ faz apropriada abordagem:

a livre iniciativa não se resume, aí, a princípio básico do liberalismo econômico ou a liberdade de desenvolvimento da empresa apenas - à liberdade única do comércio, pois. Em outros termos: não se pode visualizar no princípio tão somente uma afirmação do capitalismo.

Importante salientar que, entre as formas de iniciativa econômica, encontra-se, além da iniciativa privada, a iniciativa cooperativa (art. $5^{\circ}$, XVIII e, também, art. $174, \S \S 3^{\circ}$ e $4^{\circ}$ ), a iniciativa autogestionária e a iniciativa pública (arts. 173 e 177).

Sendo assim, atualmente, à luz dos preceitos do Estado Democrático de Direito, a atividade econômica deve buscar o equilíbrio entre geração de capital e a dignidade do trabalho, aproximando-se do entendimento de Giddens ${ }^{7}$ que define o capitalismo como "um sistema de produção de mercadorias, centrado sobre a relação entre propriedade privada do capital e o trabalho assalariado sem posse de propriedade, essa relação formando o eixo principal do sistema de classes".

Registra-se, todavia, que na sociedade pós-moderna marcada pelo consumismo, que, segundo a teoria de Bauman ${ }^{8}$, é "um atributo, a capacidade profundamente individual de querer, desejar e almejar", transformando as pessoas em mercadorias, razão pela qual somente poderão ser considerados membros da sociedade aqueles que participam das relações de consumo. A cultura contemporânea baseada no imediatismo se modifica constantemente, o que intensifica

\footnotetext{
${ }^{6}$ GRAU, Eros Roberto. A ordem econômica na constituição de 1988. 17. Ed. São Paulo: Malheiros Editores, 2015. p. 200.

7 GIDDENS, Anthony. As consequências da modernidade. 2. Ed. São Paulo: UNESP, 1991. p. 61.

${ }^{8}$ COSTA, Marisa Vorraber; CAMOZZATO, Viviane Castro. Consumo e consumismo: deslocamentos nas ressonâncias do contemporâneo. Revista Educação \& Realidade. Porto Alegre: v. 35, n. 3, set./dez., 2010. pp. $344 / 345$.
}

Rev. de Direito, Economia e Desenvolvimento Sustentável| e-ISSN: 2526-0057| Maranhão | v. 3 | n. 2 | p. 40 - 60 | Jul/Dez. 2017. 
o frequente sentimento de insatisfação, sanado por pequenos momentos intercalados pela "substituição dos desejos".

A noção de pertencimento é uma das características da sociedade de consumo e que induzem as pessoas a exercer o papel de consumidor adquirindo bens ou serviços com os quais tenha maior afinidade, uma vez que "o potencial de consumo é associado a um estilo de vida, vinculados as escolhas morais, representando a forma como se relaciona consigo mesmo e com o mundo" $" 10$.

Com efeito, no campo da solidariedade, incentiva-se o uso do poder econômico da classe empresarial na promoção de ações positivas, de natureza social, financeira, política e econômica, pautadas na sustentabilidade, que, simultaneamente, sejam vantajosas ao interesse social, promovendo o desenvolvimento da sociedade, para garantir a perpetuação das gerações futuras ${ }^{11}$.

Além disso, o interesse das empresas em patrocinar iniciativas sustentáveis serve de compensação para os atos de degradação praticados no desenvolvimento da operação mercantil, sendo ainda considerada uma maneira de demonstrar à sociedade o empenho da empresa na mudança de conduta influenciada pelas tendências de mercado ${ }^{12}$. Nessas condições, as normas constitucionais alicerçadas na consagração da dignidade da pessoa humana, conferem ao princípio da livre iniciativa contornos cada vez mais humanistas que, apoiados na função solidária, distanciam-se do aspecto relativo à lucratividade e incentivam as empresas a adotar medidas voltadas ao bem comum.

Vê-se, por conseguinte, que a liberdade de iniciativa econômica por mais que esteja positivada na lei suprema, em hipótese alguma dispõe de "termos absolutos", ou seja, está vinculada a outros valores constitucionais. Na atual conjuntura, o desenvolvimento de qualquer atividade econômica estará sujeito à observância da função solidária, invocando os direitos sociais e quaisquer outros vinculados a sociedade livre, justa, pluralista e igualitária,

\footnotetext{
${ }^{9}$ SANTIAGO, Mariana Ribeiro; CAMPELLO, Livia Gaigher Bósio. Função social e solidária da empresa na dinâmica da sociedade de consumo. Revista Scientia Iuris, Londrina: v. 20, n. 1, p. 119-143, abr. 2016, p. 123.

${ }^{10}$ FELINTO, Erick. Crowdfunding: entre as multidões e as corporações. Comunicação Mídia e Consumo. São Paulo, ano 9, v. 9, n. 26, nov. 2012, p. 148.

${ }^{11}$ SANTIAGO, Mariana Ribeiro; BEZERRO, Eduardo Buzetti Eustachio. Relações de consumo na pósmodernidade: o consumo colaborativo como instrumento de sustentabilidade. Revista de Direito da Cidade, Rio de Janeiro, v. 9, n. 2, abr. 2017, p. 474.

${ }^{12}$ COSTA, Bruna Gazzi; LORENZI, Fabiane Langon, HENNIGEN, Inês. Crowdfunding: problematizado participação social, consumo e mecanismo de visibilização. In: VI ENCONTRO NACIONAL DE ESTUDOS DO CONSUMO, 2012, Rio de Janeiro. Anais Vida Sustentável: práticas cotidianas de consumo, 2012, p. 17.
}

Rev. de Direito, Economia e Desenvolvimento Sustentável| e-ISSN: 2526-0057| Maranhão | v. 3 | n. 2 | p. 40 - 60 | Jul/Dez. 2017. 
contrariando "a lógica da competição desmedida e da indiferença ao ser humano, assumindo, enfim, uma perspectiva de cooperação, responsabilidade social, igualdade substancial e justiça distributiva social"13.

Diante das novas atribuições da classe empresarial no plano social surgem ideias inovadoras e de alto impacto, das quais o Crowdfunding se verifica como exemplo claro de convergência das características de negócio mercantil com a finalidade eminentemente social.

\section{A GLOBALIZAÇÃO E O SURGIMENTO DO CROWNDFUNDING}

O avanço da tecnologia e a rapidez na troca de informações no mundo globalizado proporcionou o rompimento do antigo modelo de sociedade. No passado, as pessoas apenas se relacionavam pessoalmente com indivíduos da mesma comunidade. Com a expansão dos meios de comunicação, as distâncias que anteriormente limitavam a visão global foram reduzidas, permitindo a aproximação dos povos e a integração com culturas e realidades completamente distintas.

Os meios de comunicação atuais foram os responsáveis por mobilizar o poder das massas, expressão que se refere a força exercida pela multidão de pessoas que se unem com a finalidade de viabilizar determinado objeto, superando obstáculos, inclusive financeiros ${ }^{14}$.

Na concepção de Anthony Giddens ${ }^{15}$, "num mundo globalizante, em que informação e imagens são rotineiramente transmitidas através do mundo, estamos todos regularmente em contato com outros que pensam e vivem de maneira diferente de nós".

Em pouco tempo, a Internet se popularizou em todas as estratificações da sociedade ${ }^{16}$. Essa interligação de conhecimento e troca de experiências possibilitou que pessoas de diferentes classes econômicas pudessem se conectar de forma digital e manter relações impessoais, unidas em prol de um objetivo comum que satisfaça os interesses individuais e, sobretudo, coletivos.

\footnotetext{
${ }^{13}$ CARDOSO, Alenilton da Silva. Princípio da Solidariedade: a confirmação de um novo paradigma. Revista Direito Mackenzie. São Paulo, v. 6, n. 1, 2012, p. 12.

${ }^{14}$ SANTOS, F. B. S., ASSAIFE; A. C. G., OLIVEIRA, Jonice. O poder das mídias sociais aplicadas em iniciativas de Crowdfunding no Brasil. IN: VIII SIMPÓSIO BRASILEIRO DE SISTEMAS DE INFORMAÇÃO (SBSI), 2012, Rio de Janeiro. Artigos, Rio de Janeiro, p. 634.

${ }^{15}$ GIDDENS, Anthony. Mundo em descontrole. 6 ed. Rio de Janeiro: Record, 2007, p. 16.

16 "Depois que a internet se tornou disponível foram necessários meros quatro anos para que 50 milhões de americanos a estivessem usando regularmente" (GIDDENS, Anthony. Mundo em descontrole. 6 ed. Rio de Janeiro: Record, 2007. p. 22).
}

Rev. de Direito, Economia e Desenvolvimento Sustentável| e-ISSN: 2526-0057| Maranhão | v. 3 | n. 2 | p. 40 - 60 | Jul/Dez. 2017. 
Nesse prisma, os investidores são convencidos pelas mídias sociais a aderir ao programa de captação de recursos destinados a concretização de projetos fomentados apenas por pessoas comuns que interagem entre si, propagando o conceito de financiamento coletivo pela rede de computadores a fim de buscar outros apoiadores ${ }^{17}$.

Em outras palavras, a comunicação eletrônica instantânea deixou de ser apenas um meio pelo qual as notícias ou informações são transmitidas mais rapidamente, passando a alterar a própria estrutura da vida das pessoas, sejam elas ricas ou pobres ${ }^{18}$.

Forçoso concluir que a Internet se disseminou em todas as classes sociais, tornandose acessível em celulares e outros dispositivos móveis, estimulando, assim, o crescimento das redes sociais. No Brasil, conforme se depreende do resultado da pesquisa Interactive Advertising Bureau realizada em 2012, a maioria das pessoas entrevistadas forneceram os seguintes dados: $65 \%$ (sessenta e cinco por cento) usam a Internet para pesquisar produtos que pretendem comprar, $57 \%$ (cinquenta e sete por cento) ficam atraídos pelos anúncios promocionais e 56\% (cinquenta e seis por cento) visitam as lojas. Com relação as mídias sociais, o tempo médio de acesso por entrevistado é de 405 (quatrocentos e cinvo) minutos no Facebook e Pinterest, 89 (oitenta e nove) minutos no Twitter, 21 (vinte e um) minutos no Linkedin e apenas 3 (três) minutos no Google Plus ${ }^{19}$.

Nesse contexto, diante das transformações sociais influenciadas pelo cenário de democratização e, consequentemente, pela limitação do Poder Estatal, consolidou-se entre os indivíduos o dever uníssono de se organizarem em favor da sociedade com o propósito de suprir as deficiências do Estado e proporcionar o bem comum.

Corroborando os efeitos da globalização sob a democracia, Giddens ${ }^{20}$ sustenta que:

A globalização está por trás da expansão da democracia. Ao mesmo tempo, paradoxalmente, ela expõe os limites das estruturas democráticas mais conhecidas, isto é, as estruturas da democracia parlamentar. Precisamos democratizar mais as instituições existentes e, fazê-lo de modo a atender as exigências da era global.

\footnotetext{
${ }^{17}$ SANTOS, op. cit., p. 633.

${ }^{18}$ GIDDENS, op. cit., p. 22.

19 SEQUEIRA, Jorge Santiago Carvalho. Crowdfunding no Brasil: Possibilidades teóricas para o sucesso do financiamento coletivo realizado via redes sociais digitais. Revista Belas Artes, 13. Ed., 2015. Disponível em: <http://www.belasartes.br/revistabelasartes/downloads/artigos/13/crowdfunding-no brasil.pdf >. Acesso em: 20 ago. 2017, p. 5.

${ }^{20}$ GIDDENS, Anthony. Mundo em descontrole. 6 ed. Rio de Janeiro: Record, 2007, p. 16.
} 
Com a mutação do conceito de Estado-nação ${ }^{21}$, a sociedade moderna acostumada com as novas tecnologias e, acima de tudo, amparada pelos ideais de justiça social e sustentabilidade permitiu a integração das massas para resolução de problemas de natureza social, cultural e político, uma vez que o crescimento das economias de mercado, na maioria das vezes, mostrase incompatível com a distribuição de rendas e o desenvolvimento da sociedade local.

Não obstante existam teorias que considerem o aumento da desigualdade social como fator negativo da globalização, nem todas as mudanças trazidas pelo desenvolvimento dos meios de comunicação foram ruins. Pode-se dizer que a troca instantânea de informações derivada do processo de globalização foi a responsável pelo início do compartilhamento de realidades sociais desconhecidas até então, o que deu ensejo a organização de grupos formados por pessoas com visões semelhantes e predileções em torno do mesmo escopo.

Em virtude do avanço das mídias sociais, a comunicação e o compartilhamento de informações torna-se a principal ferramenta na busca da justiça social e distributiva, uma vez que proporciona a integração das pessoas que se unem prol do bem estar comum. A proximidade gerada pela Internet ocasiona o início de movimentos coletivos pautados na cultura da colaboração, a exemplo disso, podem-se destacar os sites de compras coletivas, bem como o compartilhamento de espaços, de bens e serviços ${ }^{22}$.

Já é realidade, em diferentes partes do mundo, uma outra espécie de economia, gestada a partir de iniciativas, sobretudo de natureza cooperativista e associativista, oriundas da sociedade civil e dos meios populares. Mostra-se sob diferentes configurações: criação coletiva do próprio circuito de produção e consumo, alimentando cadeias socioprodutivas autônomas e, em alguns casos, não-monetarizadas, ou diferentes tipos de parcerias com os poderes públicos. É o que se chama de economia colaborativa-solidária. Como exemplos, projetam-se os bancos populares, clubes de trocas e as cooperativas sociais ${ }^{23}$.

A comunidade de escambo na Internet vem crescendo rapidamente. São cerca de 500 (quinhentos) escambos online na América do Norte e na América Latina, entre intercâmbios

\footnotetext{
21 "Os chamados Estados-nação são apenas poderosos agentes da monopolização quando invocam a soberania através da atribuição da nacionalidade" (ALBROW, Martin. Nacionalidade e Identidade na Era Global. Globalização e Identidade Nacional. São Paulo: Atlas, 1999. p. 30).

${ }^{22}$ SILVA, W. S., FREITAS, J. C. A abordagem sistêmica para o Crowdfunding no Brasil: um estudo exploratório - visão sistêmica dos negócios. In: $8^{\circ}$ CONGRESSO BRASILEIRO DE SISTEMAS, Revista Gestão \& Conhecimento. Poços de Caldas, nov. 2012, p. 316-317.

${ }^{23}$ FRANÇA FILHO, Genauto Carvalho de e LAVILLE, Jean-Louis. A economia solidária: uma abordagem internacional. Porto Alegre: Editora da UFRGS, 2004. p. 15.
}

Rev. de Direito, Economia e Desenvolvimento Sustentável| e-ISSN: 2526-0057| Maranhão | v. 3 | n. 2 | p. 40 - 60 | Jul/Dez. 2017. 
menores, voltados para uma comunidade específica, e grandes intercâmbios abertos. Apenas em 2008, o equivalente a mais de US\$10.000.000.000,00 (dez bilhões de dólares americanos) em mercadorias foram trocados por mais de 400 (quatrocentas) mil empresas globalmente ${ }^{24}$.

Não há, contudo, como se prever os rumos que seguirá o consumo colaborativo. Não é possível dizer quanto, quão longe e quão rápido ele vai crescer, mesmo em face das fortes tendências de evolução deste fenômeno socioeconômico até 2015. Não se trata, certamente, de uma iniciativa que vai contra as empresas, pois estas continuarão vendendo e as pessoas continuarão comprando. As expectativas são de uma melhora no perfil dos consumidores e na maneira de consumir, bem como um afastamento da cultura hiperindividualista ${ }^{25}$.

Além disso, a evolução tecnológica permitiu que pessoas comuns e desconhecidas entre si pudessem se organizar no intuito de angariar fundos capazes de viabilizar de maneira independente o projeto de interesse mútuo. Esse modelo de geração de receitas financeiras resulta no embrião do microfinanciamento coletivo, chamado de Crowdfunding ${ }^{26}$.

Os primeiros registros de iniciativas voltadas ao compartilhamento de recursos financeiros pelo poder das massas são de 1976 quando o Banco Yunus Grameen situado em Bangladesh autorizou a concessão de microcrédito, sem nenhuma burocracia ou garantias de qualquer tipo, a pequenas empresas que não dispunham de capital para subsidiar o negócio. $\mathrm{O}$ incentivo destinado as pessoas físicas e jurídicas de baixa renda obteve reconhecimento mundial, em 2006, com a entrega do Prêmio Nobel ao fundador da Instituição Bancária ${ }^{27}$.

Nos anos subsequentes, a cultura participativa se disseminou em diversos ramos, atraindo milhares de pessoas que se mobilizavam, geralmente, por meio de desembolso de valores monetários para consecução de determinado objetivo. Exemplo disso está o financiamento do disco da Banda Britânia Marillion em 1997 que, apoiada no fanatismo de seus fãs, arrecadaram durante uma turnê nos Estados Unidos da América a quantia de US\$ 60.000,00 (sessenta mil dólares americanos), que posteriormente seria convertida para gravação do próximo trabalho da banda.

\footnotetext{
${ }^{24}$ BOTSMAN, Rachel e ROGERS, Roo. O que é meu é seu: como o consumo colaborativo vai mudar o nosso mundo. Trad. Rodrigo Sardenberg. Porto Alegre: Bookman, 2011. p. 132.

${ }^{25}$ Ibid., pp. 150-151.

${ }^{26}$ SANTOS, Fernanda Bruno dos; OLIVEIRA, Jonice. Os novos mecenas: um estudo sobre Crowdfunding no Brasil através das mídias sociais. Universidade Federal do Rio de Janeiro, 2015, Disponível em: <http://www.lbd.dcc.ufmg.br/bdbcomp/servlet/Trabalho?id=12015>. Acesso em: 20 ago. 2017, pp. 01-04.

${ }^{27}$ Página que pode ser acessada pela internet: https://www.yunusnegociossociais.com/muhammad-yunus.
} 
Em que pesem as características da cultura participativa na era da modernidade tardia, tal prática de arrecadação de valores não pode ser confundida com o conceito de mecenato, termo este que faz alusão ao patrocínio de artistas durante o período renascentista. O financiamento da pós-modernidade refere-se à associação de pessoas com interesses recíprocos que se unem para custear determinado evento ou projeto, sejam eles de natureza social ou não. Por outro lado, o financiamento oriundo do mecenato se dava pelo apoio pecuniário dos nobres, clero e realeza como forma de incentivo as produções artísticas, como, pintores, escritores e cientistas da época do renascimento cultural dos Séculos XV e XVI ${ }^{28}$.

Assim, com a modernização dos meios telemáticos e a divulgação das ações motivadas pela cultura colaborativa, os Estados Unidos da América se tornaram os pioneiros no desenvolvimento de negócios tecnológicos. Aproveitando o sucesso das mídias sociais, o então candidato a Presidência dos Estados Unidos da América, Barack Obama, com o apoio do desenvolvedor do Facebook e de outros sites, lançou nas redes de relacionamento a campanha política com o slogan Yes, we can. O projeto se pulverizou rapidamente entre os usuários e obteve mais de três milhões de doações de seguidores de todas as etnias e classes sociais. A arrecadação promovida pela Internet foi responsável pelo custeio de $87 \%$ (oitenta e sete por cento) de todas as despesas do processo eleitoral ${ }^{29}$.

Nesse ambiente hightech destinado a atrair os interessados e obter a captação dos valores, os potenciais doadores tem acesso aos detalhes e conteúdos do projeto, visualizando vídeos e imagens explicativas produzidas pelo proponente e, se estiverem convencidos dos benefícios do citado projeto, os investidores promovem as doações, por ato volitivo e espontâneo, cujos valores são transferidos à plataforma digital após o preenchimento do cadastro pelo participante, no qual ele autoriza a concretização da operação bancária e o repasse online dos valores por intermédio da plataforma ou de outras soluções cibernéticas, que asseguram a transmissão segura de quantias financeiras, impedindo a ocorrência de golpes.

Superada essa etapa inaugural de conhecimento entre os usuários norte americanos, o fenômeno do Crowdfunding - expressão em inglês que significa financiamento coletivo difundiu-se por mais de 160 (cento e sessenta) países. No Brasil, a primeira plataforma digital

\footnotetext{
${ }^{28}$ LIMA, Leandro Augusto Borges. Notas sobre sociabilidade, consumo e crowdfunding. In: COMUNICON, 2012, São Paulo. Anais, São Paulo, ESPM, 2012, p. 02.

${ }^{29}$ Página que pode ser acessada pela internet: https://pt.slideshare.net/arantes/barack-obama-case-em-mdiassociais-presentation.
}

Rev. de Direito, Economia e Desenvolvimento Sustentável| e-ISSN: 2526-0057| Maranhão | v. 3 | n. 2 | p. 40 - 60 | Jul/Dez. 2017. 
foi criada em 2011 e, desde então, o Catarse se tornou o maior portal de projetos virtuais do país, com mais de 390.000 (trezentos e noventa mil) apoiadores, chegando após 6 (seis) anos de divulgação ao recorde de $\mathrm{R} \$ 60.000 .000,00$ (sessenta milhões de reais) captados de uma multidão de pessoas interessadas em colocar em prática as ideias inovadoras com potencial de melhorar da vida dos brasileiros ${ }^{30}$.

Existem projetos dos mais variados temas, desde a inclusão social e valorização da diversidade, como a proteção de indígenas e atos de repúdio ao racismo, preconceito e discriminação, como também, ações de impacto e inovação que, geralmente, são propostas por mentes criativas ou empreendedores em busca de capital para colocar em prática as ações de caráter inovador, tendo em vista que os sujeitos do Crowdfunding apresentam a racionalidade mercantil chamada por Foucault de "individuo-empresa"31.

Para alcançar o sucesso, o criador do projeto deve se preocupar com o planejamento do tema submetido à apreciação de terceiros e, principalmente, desenvolver o poder de convencimento e estratégica de marketing para angariar fundos. Os mecanismos de visibilização são ferramentas indispensáveis para que o projeto se torne atrativo aos investidores que navegam pela Internet ${ }^{32}$. Segundo os dados da plataforma, a probabilidade de êxito a partir da segunda campanha é de $75 \%$ (setenta e cinco por cento) comparado com o índice de adesão da primeira, isso porque a cada lançamento o idealizador adquire experiência para lidar com críticas e solucionar eventuais problemas que possam interferir na divulgação da iniciativa perante os investidores ${ }^{33}$.

Antes de adentrar aos aspectos jurídicos dessa "nova" tendência mundial, convém tecer as definições sobre esse fenômeno de geração de recursos, chamado Crowdfunding.

Segundo as informações extraídas de consultorias financeiras e sites especializados, a análise dos mecanismos que compõem o Crowdfunding permite se chegar ao seguinte conceito: modelo de negócio criado para captação de investimentos de terceiros, por meio de plataforma virtual, com a finalidade de estruturar projetos ou empresas de interesse coletivo, cujos

\footnotetext{
30 Página que pode ser acessada pela internet: http://blog.catarse.me/60-milhoes-apoiados-catarse-recordefinanciamento-coletivo/.

31 COSTA, Bruna Gazzi; LORENZI, Fabiane Langon, HENNIGEN, Inês. Crowdfunding: problematizado participação social, consumo e mecanismo de visibilização. In: VI ENCONTRO NACIONAL DE ESTUDOS DO CONSUMO, 2012, Rio de Janeiro. Anais Vida Sustentável: práticas cotidianas de consumo, 2012, p. 5.

32 Ibid., p. 8.

33 Página que pode ser acessada pela internet: http://blog.catarse.me/60-milhoes-apoiados-catarse-recordefinanciamento-coletivo/.
} 
financiadores serão remunerados com percentual definido sobre o sucesso do projeto ou simplesmente pela satisfação de vê-lo realizado.

Baseado nas hipóteses de programas voltados à captação de valores, observa-se que o financiamento coletivo possui quatro modalidades distintas: (i) doações, (ii) recompensas, (iii) Equity Crowdfunding e a (iv) Debt Crowdfunding. Todos os tipos de financiamento se diferenciam pelo perfil dos apoiadores e, também, pela contraprestação que resultará da contribuição financeira destinada ao projeto.

No primeiro caso, como o próprio nome diz, o investidor convencido da importância da causa que se destina ao bem da coletividade oferece "doações" em dinheiro, não havendo, entretanto, nenhuma contrapartida, haja vista o caráter assistencialista.

Conveniente asseverar que a finalidade da arrecadação neste caso é a "mobilização de causas sociais e filantrópicas de projetos humanitários e segue um modelo de patrocínio, cujos doadores não pretendem retorno financeiro direito do montante doado"34.

Na segunda opção denominada de "recompensas", o valor injetado no projeto pelo patrocinador é revertido na forma de "brindes" ou amostras dos "produtos ou serviços" sobre os quais se refere a campanha. Geralmente o fundo é destinado a "shows, publicações, filmes e outras iniciativas relacionadas à arte e à cultura"35. Tal modalidade é conhecida também como "tudo ou nada", isto é, se o montante das contribuições não atingir o valor total que se pretende levantar no projeto, todos os donativos retornam aos seus respectivos investidores.

As duas últimas modalidades (Equity e Debt Crowdfunding) se diferem das demais, uma vez que as características se assemelham as operações de bancos e fundos de investimento. Embora a finalidade do dinheiro aplicado no projeto seja fomentar atividades de ordem inovadora e tecnológica, a pretensão do investidor é alcançar o retorno financeiro. Na Equity Crowdfunding o aporte de recursos é direcionado a compra de ações ou títulos de empresas de pequeno porte, geralmente de Startups, das quais o financiador se torna sócio ou acionista e passa a integrar o capital social do empreendimento ${ }^{36}$.

A última espécie de financiamento, o Debt Crowdfunding consiste no adiantamento do aporte financeiro que, depois de determinado período, conforme cronograma fixado nas regras do projeto, o empréstimo conferido será restituído ao patrocinador acrescido de juros.

\footnotetext{
${ }^{34}$ MELLO, Patrícia Alencar Silva, MENDES, Leilani Dian. Equity Crowdfunding: Solução de investimento para constituição de pequenas e médias empresas?. João Pessoa: CONPEDI/UFPB, 2014. pp. 345

${ }^{35}$ Ibid., p. 350.

${ }^{36}$ MELLO, Patrícia Alencar Silva, MENDES, Leilani Dian. Equity Crowdfunding: Solução de investimento para constituição de pequenas e médias empresas?. João Pessoa: CONPEDI/UFPB, 2014, p. 347.
} 
Em ambos os casos (Equity e Debt Crowdfunding) por serem adaptações do financiamento colaborativo original e deturparem a finalidade do instituto do Crowdfunding, mesmo que o escopo da iniciativa seja alcançado, a verdadeira pretensão dos investidores é ampliar o investimento por meio de operações similares ao mercado de capitais, o que enseja a fiscalização da Comissão de Valores Mobiliários (CVM).

Cabe salientar que a Comissão de Valores Mobiliários (CVM), através da Instrução CVM 588/2017, autorizou as companhias com receita anual de até R\$10.000.000,00 (dez milhões de reais) a oferecerem até $\mathrm{R} \$ 5.000 .000,00$ (cinco milhões de reais) em ações por meio de aplicativos de Crowdfunding. Para tanto, a oferta de ações dispensa o registro de na CVM, mas os aplicativos precisam ser cadastrados e autorizados pela CVM.

Com exceção das hipóteses acima, nas quais o investidor - apesar de selecionar projetos que poderão trazer benefícios ao bem comum - tem a intenção de aplicar seu dinheiro em algo rentável, unindo o útil ao agradável, ou seja, apoiando empresas com elevado potencial beneficentes, mas, que no final das contas, desenvolvam atividades lucrativas. Por fim, os outros tipos de financiamento (doações e recompensas) dispõem de caráter estritamente social e que se amoldam aos conceitos de empreendimento à luz da função solidária.

Nesse cenário, consolida-se o princípio da solidariedade, responsável pela valorização dos direitos difusos, o que despertou nos entes da sociedade contemporânea o desejo de desenvolver ações que, direta ou indiretamente, possam melhorar as suas condições de vida da população $^{37}$.

\section{A FUNÇÃO SOLIDÁRIA DO CROWDFUNDING}

O atual sistema capitalista cedeu as tendências do Estado Democrático e se desprendeu do retrogrado modo de produção disseminado no Estado Liberal. Desse modo, por força dos preceitos constitucionais estes impuseram à classe empresarial o rompimento com os paradigmas do passado. O equilíbrio passou a ser foco das relações empresariais, conforme estabelecem os princípios da ordem econômica, preceituados no artigo 170, da Carta Política.

Nessa senda, fundadas no capitalismo equânime e socialmente humanizado, as empresas contemporâneas devem desenvolver atividades baseadas na função solidária, observando as normas de proteção ao meio ambiente e de regras de combate ao consumismo

${ }^{37}$ CARDOSO, Alenilton da Silva. Princípio da Solidariedade: a confirmação de um novo paradigma. Revista Direito Mackenzie. São Paulo, v. 6, n. 1, 2012, p. 13.

Rev. de Direito, Economia e Desenvolvimento Sustentável| e-ISSN: 2526-0057| Maranhão | v. 3 | n. 2 | p. 40 - 60 | Jul/Dez. 2017. 
exacerbado, ou seja, com o nítido propósito de contribuir para o desenvolvimento social pautado no principio da dignidade da pessoa humana.

Destarte, com os avanços nos campos da justiça social, verificou-se que a atuação das atividades empresariais podem ter ainda maior efetividade sob o prisma da solidariedade social, estatuída no artigo $3^{\circ}$, I, da Constituição Federal.

Referência no tema da solidariedade, Edgar $\operatorname{Morin}^{38}$ ensina que

em nosso mundo de homens, no qual as forças de separação, recolhimento, ruptura, deslocamento, ódio, são cada vez mais poderosas, mais do que sonhar com a harmonia geral ou com o paraíso, devemos reconhecer a necessidade vital, social e ética de amizade, de afeição e de amor pelos seres humanos, os quais, sem isso, viveriam de hostilidade e de agressividade, tornando-se amargos ou perecendo.

$\mathrm{Na}$ aclamada obra "A Via para o futuro da humanidade", o referido autor ${ }^{39}$ destaca, ainda:

A solidariedade anônima do Estado-Providência, com seus dispositivos de segurança e assistências de todas as ordens, é insuficiente. Há necessidade de uma solidariedade concreta e vivenciada, de pessoa para pessoa, de grupos para pessoas, de pessoa para grupos. (...) Não se trata, contudo, de promulgar a solidariedade, mas de liberar a força não empregada das boas vontades e de favorecer as ações de solidariedade. Segundo nossa concepção do indivíduo-sujeito, todo sujeito humano tras consigo dois quasesoftwares: um é o da autoafirmação egocêntrica que o Ego-Eu expressa, vital para se alimentar, se defender, se desenvolver; o outro é os software do Nós, que inscreve o Eu em uma relação de amor ou de comunidade no seio de sua familia, de sua pátria, de seu pertencimento religioso, de seu partido. Nossa civilização superdesenvolveu o primeiro software e subdesenvolveu o segundo. Mas este encontra-se apenas adormecido; trata-se de incitá-lo a despertar.

Ao relacionar solidariedade e justiça, Habermas ${ }^{40}$ afirma que:

A justiça concebida deontologicamente exige, como sua outra face, a solidariedade.
Não se trata, neste caso, de dois momentos que se complementam, mas de aspectos
da mesma coisa. Toda moral autônoma tem que resolver, ao mesmo tempo, duas
tarefas: ao reivindicar trato igual, e com ele um respeito equivalente pela dignidade
de cada um, faz valer a inviolabilidade dos indivíduos na sociedade; e ao mesmo
tempo em que exige a solidariedade por parte dos indivíduos, como membros de uma
comunidade na qual são socializados, protege as relações intersubjetivas de
reconhecimento recíproco. A justiça refere-se à igualdade da liberdade dos indivíduos
que se determinam a si mesmos e que são insubstituíveis, enquanto a solidariedade

${ }^{38}$ MORIN, Edgar. O Método VI: ética. 2. ed. Tradução de Juremir Machado da Silva. Porto Alegre: Porto Alegre: Sulina, 2005. p. 36.

${ }^{39}$ Id., 2013. pp. 76-77.

${ }^{40}$ HABERMAS, Jürgen. Aclaraciones a la ética del discurso. Madrid: Trotta, 2000. pp. 75-76.

Rev. de Direito, Economia e Desenvolvimento Sustentável| e-ISSN: 2526-0057| Maranhão | v. 3 | n. 2 | p. 40 - 60 | Jul/Dez. 2017. 
refere-se ao bem, ou à felicidade dos companheiros irmanados em uma forma de vida intersubjetivamente compartilhada, e deste modo também à preservação da integridade dessa forma de vida. As normas não podem proteger um sem o outro, isto é, não podem proteger a igualdade de direitos e as liberdades dos indivíduos sem o bem do próximo e da comunidade a que eles pertencem.

O fato de a solidariedade estar materializada na Constituição Federal brasileira como um dos objetivos do Estado Democrático de Direito enseja sua aplicabilidade imediata na esfera empresarial, conferindo aos detentores do poder econômico o dever de praticar ações que superem a expectativa das leis vigentes no ordenamento jurídico. $\mathrm{O}$ desenvolvimento de iniciativas que tempos atrás eram de responsabilidade exclusiva do Poder Público se disseminaram no âmbito da iniciativa privada, ganhando notoriedade os conceitos de desenvolvimento sustentável, consumo colaborativo e economia compartilhada, sobre os quais Mariana Ribeiro Santiago e Eduardo Buzetti Eustachio Bezerro ${ }^{41}$ fazem as pertinentes elucidações:

[....] o consumo colaborativo é uma das principais ferramentas da conscientização sobre a desnecessidade da exploração desenfreada de recursos naturais para a manutenção da necessidade do consumo como meio de o indivíduo sentir-se integrado e participativo da vida social, reflexos da era pós-moderna, em que não somos valorizados como coletividade, mas marcados pelo individualismo, e ânsia do "ter" em detrimento dos valores essenciais do ser.

A era do consumismo aflorado que resulta na alienação radical do ser humano nada mais é do que consequência da violação ao princípio da solidariedade social, visto que na ausência de racionalidade provocada pela imersão do indivíduo no fenômeno do consumismo, exclui os direitos básicos tutelados pelo texto constitucional e, via de consequência, suprime a dignidade mínima para viver em sociedade.

Desse modo, as atividades empresariais no contexto da pós-modernidade passam a ser norteadas sob o viés da sustentabilidade. Além disso, o exercício da exploração empresarial na perspectiva da função solidária transcende as obrigações legais e assume uma posição de grande relevância para continuidade da vida social, ou seja, criar condições de desenvolvimento econômico sem impactar em elementos básicos que possam limitar a evolução das gerações vindouras.

\footnotetext{
${ }^{41}$ SANTIAGO, Mariana Ribeiro; BEZERRO, Eduardo Buzetti Eustachio. Relações de consumo na pósmodernidade: o consumo colaborativo como instrumento de sustentabilidade. Revista de Direito da Cidade, Rio de Janeiro, v. 9, n. 2, abr. 2017, pp. 474-475.
}

Rev. de Direito, Economia e Desenvolvimento Sustentável| e-ISSN: 2526-0057| Maranhão | v. 3 | n. 2 | p. 40 - 60 | Jul/Dez. 2017. 
Convém transcrever, a propósito da elucidação do tema, o conceito de sustentabilidade manifestado por Mariana Ribeiro Santiago e Pedro Antônio de Oliveira Machado ${ }^{42}$ nos âmbitos social, econômico e ambiental:

[...] a sustentabilidade social revela-se por meio de iniciativa voltadas a melhorar a
qualidade de vida da população, buscar equilíbrio e o bem-estar da sociedade,
auxiliando os membros dessa sociedade que enfrentam condições desfavoráveis. Já a
sustentabilidade econômica está ligada à preocupação de distribuição intertemporal
de recursos naturais finitos, o que pressupõe a definição de limites para o seu uso em
escala comercial (OLIVEIRA, 2010, pp. 14-21). Por fim, a sustentabilidade ambiental
busca a difícil harmonia entre a exploração dos recursos naturais e manutenção do
equilíbrio do meio ambiente, de forma a atender as necessidades do presente, sem
comprometer a qualidade de vida imediata, além de preservar o planeta para as futuras
gerações.

Nesse contexto, destacam-se projetos de cunho social, cultural e tecnológico disseminados pelo ambiente virtual, sendo este responsável pela integração de indivíduos com as mesmas afinidades, entre os quais permeia a cultura da convergência, "curso de conteúdos por diversas plataformas de comunicação, ampliando a possibilidade de transição do público nessas múltiplas plataformas atrás de seus interesses pessoais, possibilitando novas experiências" ${ }^{\prime 3}$.

Resta evidente, por meio de análise sociológica, que a sociabilidade proporcionada pelos meios telemáticos fomentou a constituição de grupos que se uniram em prol de objetivos específicos. Essa característica marcada pela colaboração deu origem ao modelo de negócio denominado Crowdfunding. Trata-se de "prática social intimamente ligada à interação dos sujeitos" ${ }^{4}$, cujas contribuições individuais de natureza pecuniária permitem a concretização de projetos voltados à melhoria da qualidade de vida dos entes da sociedade.

Em outras palavras, através do uso de plataformas digitais, o Crowdfunding transforma-se num processo em que os usuários colaboram para o financiamento de um projeto, na linha da solidariedade social, desenvolvendo o que se pode chamar de "a inteligência coletiva, a cultura participativa e a sabedoria das multidões" ${ } 45$.

\footnotetext{
42 SANTIAGO, Mariana Ribeiro; MACHADO, Pedro Antônio de Oliveira. Empresa, sustentabilidade $e$ responsabilidade social: origens, motivações, críticas e aspectos práticos. Revista de Direito e Sustentabilidade, v.1, n.2, p. 95-118, jul/dez. 2015. pp. 99-100.

${ }^{43}$ DIAS, Natália. Crowdfunding: recompensas são engrenagens do financiamento colaborativo?. In: IV CONECO, 2013, Rio de Janeiro. Anais, Rio de Janeiro, UERJ, 2013, p. 04.

${ }^{44}$ LIMA, Leandro Augusto Borges. Notas sobre sociabilidade, consumo e crowdfunding. In: COMUNICON, 2012, São Paulo. Anais, São Paulo, ESPM, 2012. p. 08.

${ }^{45}$ FELINTO, Erick. Crowdfunding: entre as multidões e as corporações. Comunicação Mídia e Consumo. São Paulo, ano 9, v. 9, n. 26, nov. 2012. p. 140-141.
} 
Salientando a importância da identificação pessoal dos patrocinadores com o conteúdo do projeto de Crowdfunding, Leandro Augusto Borges de Lima ${ }^{46}$ descreve que:

\begin{abstract}
A ação coletiva é um dos possíveis usos benéficos do nosso excedente cognitivo, e o crowdfunding se insere aqui, como verificaremos adiante. Shirky ressalta que estamos vivendo em meio a um extraordinário aumento de nossa capacidade de compartilhar, de cooperar uns com os outros e de empreender ações coletivas, tudo isso for a de instituições e organizações tradicionais.
\end{abstract}

A difusão social de novas ideias conjecturadas por pessoas criativas e financiadas por terceiros através da cooperação mútua torna-se o embrião de "novas" atividades empresariais que já nascem em uma sociedade evoluída, com padrões éticos e, sobretudo, pautada na responsabilidade social e nos parâmetros de sustentabilidade, já que a função solidária é aquela que traz uma contribuição valorosa para o desenvolvimento social ${ }^{47}$.

Cumpre consignar, ademais, que a solidariedade intrínseca aos negócios mercantis oriundos do financiamento coletivo impõe o dever de cooperação e assistência aos entes da sociedade como forma de recompensar o apoio obtido da multidão de parceiros, sendo vedado qualquer tipo de lucro ou vantagem pessoal advindos da "imagem" veiculada nos mecanismos de publicidade proporcionados pela plataforma digital.

As Startups são exemplos claros desse modelo hodierno de empresas custeadas pela captação de recursos de terceiros que fomentam a produção da atividade econômica adaptada ao contexto de democratização que, além de gerar riquezas e estimular o desenvolvimento da economia, jamais deverá se desvirtuar dos interesses sociais, sob pena de intervenção do Estado.

No Brasil podem ser encontrados inúmeros portais destinados a realização do Crowdfunding, cujos principais (com exceção do Catarse) são Let's (www.lets.bt), Vakinha (www.vakinha.com.br), Vamos agir! (www.vamosagir.com), Eu patrocino (www.eupatrocino.com.br), dentre outros. Além disso, o idealizador do projeto poderá aprimorar sua iniciativa em diversos grupos de discussão, dos quais o mais famoso é centro de debates de Crowdfunding do Google (http://groups.google.com/group/crowfunding?pli=1) ${ }^{48}$.

O financiamento coletivo mostra-se, dessa forma, como uma técnica importante de incentivo a consciência coletiva, de modo que as pessoas interligadas pelo ambiente tecnológico

\footnotetext{
${ }^{46}$ LIMA, Leandro Augusto Borges. Notas sobre sociabilidade, consumo e crowdfunding. In: COMUNICON, 2012, São Paulo. Anais, São Paulo, ESPM, 2012, p. 06.

${ }^{47}$ SANTIAGO, Mariana Ribeiro; CAMPELLO, Livia Gaigher Bósio. Função social e solidária da empresa na dinâmica da sociedade de consumo. Revista Scientia Iuris, Londrina, v. 20, n. 1, p. 119-143, abr. 2016. p. 136.

${ }^{48}$ SILVA, W. S., FREITAS, J. C. A abordagem sistêmica para o Crowdfunding no Brasil: um estudo exploratório - visão sistêmica dos negócios. In: $8^{\circ}$ CONGRESSO BRASILEIRO DE SISTEMAS, Revista Gestão \& Conhecimento. Poços de Caldas, nov. 2012, p. 322.
}

Rev. de Direito, Economia e Desenvolvimento Sustentável| e-ISSN: 2526-0057| Maranhão | v. 3 | n. 2 | p. 40 - 60 | Jul/Dez. 2017. 
promovam atos de cooperação e assistencialismo em torno de um objeto em comum, geralmente de cunho social, que lhes permitam desenvolver a solidariedade social e torná-los protagonistas de projetos que contribuam para redução da desigualdade social, erradicação da pobreza e promovam a justiça social e, notadamente, a sustentabilidade dos atos mercantis.

\section{CONCLUSÃO}

Diante do exposto nos tópicos declinados neste artigo, constata-se que o financiamento coletivo amplamente disseminado nos meios virtuais, é o resultado da integração de três sujeitos: o proponente (criador do projeto), o investidor (doador de verba pecuniária) e a plataforma digital que atua como intermediador entre os outros dois.

É possível verificar que a iniciativa estudada está perfeitamente caracterizada como um fenômeno da era digital, da pós-modernidade, profundamente dependente das ideias de tecnologia, Internet e globalização, mostrando-se como uma forma de integração entre indivíduos.

Trata-se, nessa linha, de uma modalidade inovadora de geração de recursos financeiros destinados à implementação de projetos, geralmente de ordem social, educacional e cultural, que se mostra como uma alternativa às formas tradicionais de captação de recursos.

Embora as campanhas de Crowdfunding sejam veiculadas no âmbito virtual, com a divulgação das ideias nas plataformas digitais, os projetos poderão se transformar em atividades econômicas, como, por exemplo, a criação de startups ou outras empresas modeladas pela conjugação dos fatores da livre iniciativa e valor social do trabalho.

Mesmo nas hipóteses em que o Crowdfunding traz no seu íntimo o desejo de atingir a lucratividade, observa-se que, simultaneamente, contribui para a realização da justiça distributiva e zela pela dignidade de todos os entes da sociedade moderna.

Analisado o âmago da iniciativa (Crowdfunding), nota-se que se trata de um expoente da economia colaborativa, calcada na noção de solidariedade social, contribuindo, desta forma, para a questão da sustentabilidade, nos prismas ambiental, econômico e social, colaborando para uma sociedade mais saudável e para um quadro que preserva os interesses das futuras gerações. 


\section{REFERÊNCIAS}

ALBROW, Martin. Nacionalidade e Identidade na Era Global. Globalização e Identidade Nacional. São Paulo: Atlas, 1999.

BONAVIDES, Paulo. Do Estado liberal ao Estado social. 9. Ed. São Paulo: Malheiros Editores, 2009.

BOTSMAN, Rachel; ROGERS, Roo. O que é meu é seu: como o consumo colaborativo vai mudar o nosso mundo. Trad. Rodrigo Sardenberg. Porto Alegre: Bookman, 2011.

CARDOSO, Alenilton da Silva. Princípio da Solidariedade: a confirmação de um novo paradigma. Revista Direito Mackenzie, São Paulo, v. 6, n. 1, p. 10-29, 2012.

COMPARATO, Fábio Konder. A afirmação histórica dos direitos humanos. 7. Ed. São Paulo: Saraiva, 2010.

COSTA, Marisa Vorraber; CAMOZZATO, Viviane Castro. Consumo e consumismo: deslocamentos nas ressonâncias do contemporâneo. Revista Educação \& Realidade. Porto Alegre, v. 35, n. 3, p. 343-349, set/dez. 2010.

COSTA, Bruna Gazzi; LORENZI, Fabiane Langon, HENNIGEN, Inês. Crowdfunding: problematizado participação social, consumo e mecanismo de visibilização. In: VI ENCONTRO NACIONAL DE ESTUDOS DO CONSUMO, 2012, Rio de Janeiro. Anais Vida Sustentável: práticas cotidianas de consumo, 2012, p. 01-20.

DIAS, Natália. Crowdfunding: recompensas são engrenagens do financiamento colaborativo?. In: IV CONECO, 2013, Rio de Janeiro. Anais, Rio de Janeiro, UERJ, 2013, p. 01-14.

FELINTO, Erick. Crowdfunding: entre as multidões e as corporações. Comunicação Mídia e Consumo. São Paulo, ano 9, v. 9, n. 26, nov. 2012.

FRANÇA FILHO, Genauto Carvalho de e LAVILLE, Jean-Louis. A economia solidária: uma abordagem internacional. Porto Alegre: Editora da UFRGS, 2004.

GRAU, Eros Roberto. A ordem econômica na constituição de 1988. 17. Ed. São Paulo: Malheiros Editores, 2015.

GIDDENS, Anthony. Mundo em descontrole. 6 ed. Rio de Janeiro: Record, 2007.

GIDDENS, Anthony. As consequências da modernidade. 2 ed. São Paulo: UNESP, 1991.

HABERMAS, Jürgen. Aclaraciones a la ética del discurso. Madrid: Trotta, 2000.

LIMA, Leandro Augusto Borges. Notas sobre sociabilidade, consumo e crowdfunding. In: COMUNICON, 2012, São Paulo. Anais, São Paulo, ESPM, 2012, p. 01-14. 
MELLO, Patrícia Alencar Silva, MENDES, Leilani Dian. Equity Crowdfunding: Solução de investimento para constituição de pequenas e médias empresas?. João Pessoa: CONPEDI/UFPB, pp. 340-365, 2014.

MORIN, Edgar. A via para o futuro da humanidade. Tradução de Edgard de Assis Carvalho e Mariza Perassi Bosco. Rio de Janeiro: Bertrand Brasil, 2013.

MORIN, Edgar. O Método VI: ética. 2. ed. Tradução de Juremir Machado da Silva. Porto Alegre: Porto Alegre: Sulina, 2005.

SANTIAGO, Mariana Ribeiro; BEZERRO, Eduardo Buzetti Eustachio. Relações de consumo na pós-modernidade: o consumo colaborativo como instrumento de sustentabilidade. Revista de Direito da Cidade, Rio de Janeiro, v. 9, n. 2, p. 463-481, abr. 2017.

SANTIAGO, Mariana Ribeiro; CAMPELLO, Livia Gaigher Bósio. Função social e solidária da empresa na dinâmica da sociedade de consumo. Revista Scientia Iuris, Londrina, v. 20, n. 1, p. 119-143, abr. 2016.

SANTIAGO, Mariana Ribeiro; MACHADO, Pedro Antônio de Oliveira. Empresa, sustentabilidade e responsabilidade social: origens, motivações, críticas e aspectos práticos. Revista de Direito e Sustentabilidade, v.1, n.2, p. 95-118, jul/dez. 2015.

SANTOS, F. B. S., ASSAIFE; A. C. G., OLIVEIRA, Jonice. O poder das mídias sociais aplicadas em iniciativas de Crowdfunding no Brasil. IN: VIII SIMPÓSIO BRASILEIRO DE SISTEMAS DE INFORMAÇÃO (SBSI), 2012, Rio de Janeiro. Artigos, Rio de Janeiro, pp. 631-635.

SANTOS, Fernanda Bruno dos; OLIVEIRA, Jonice. Os novos mecenas: um estudo sobre Crowdfunding no Brasil através das mídias sociais. Universidade Federal do Rio de Janeiro, 2015, Disponível em: 〈http://www.lbd.dcc.ufmg.br/bdbcomp/servlet/Trabalho?id=12015>. Acesso em: 20 ago. 2017.

SEQUEIRA, Jorge Santiago Carvalho. Crowdfunding no Brasil: Possibilidades teóricas para o sucesso do financiamento coletivo realizado via redes sociais digitais. Revista Belas Artes, 13. $\quad 2015.2$ Disponível em: <http://www.belasartes.br/revistabelasartes/downloads/artigos/13/crowdfunding-no brasil.pdf. Acesso em: 20 ago. 2017.

SILVA, W. S., FREITAS, J. C. A abordagem sistêmica para o Crowdfunding no Brasil: um estudo exploratório - visão sistêmica dos negócios. In: $8^{\circ}$ CONGRESSO BRASILEIRO DE SISTEMAS, Revista Gestão \& Conhecimento. Poços de Caldas, nov. 2012, p. 316-334.

WAMBIER, Luciane. A função social da empresa e o princípio da solidariedade: instrumentos de cristalização dos valores sociais na estrutura jurídico-trabalhista. Revista do Tribunal Regional do Trabalho da 15ª Região, Campinas, n. 42, jan/jun. 2013.

Rev. de Direito, Economia e Desenvolvimento Sustentável| e-ISSN: 2526-0057| Maranhão | v. 3 | n. 2 | p. 40 - 60 | Jul/Dez. 2017. 